\title{
The Effects of Global Education in the English Language Conversation Classroom
}

\author{
Reza Omidvar ${ }^{1} \&$ Benjamin Sukumar ${ }^{2}$ \\ ${ }^{1}$ Department of Studies of Linguistics, University of Mysore, Mysore, India \\ ${ }^{2}$ Institute of Language Studies, Mysore, India \\ Correspondence: Reza Omidvar, Department of Studies in Linguistics, University of Mysore, Mysore, India. Tel: \\ 991-629-5813. E-mail: reza.omidvar.research@gmail.com
}

Received: January 17, 2013 Accepted: May 8, 2013 Online Published: June 3, 2013

doi:10.5539/elt.v6n7p151 URL: http://dx.doi.org/10.5539/elt.v6n7p151

\begin{abstract}
Global education is the backbone of balanced teaching. This is also applicable in the second language teaching domain where its application could result in enhancing global awareness and the linguistic competence of learners. It is, however, important to consider the platform of teaching English to speakers of other languages where the participant's content as well as task plays an important role in enhancing the learning curve.

With the above as a theoretical background, this study puts global issues into practice within the content of a syllabus of English language teaching in an intermediate, multilingual and multi- cultural conversation class at the Institute Of Language Studies (IOLS), India, producing competent students. The effect of integrated global education in teaching English as a second language has been qualitatively evaluated throughout the course of the experiment. Global education issues are investigated, amalgamating the content-based and task-based language teaching methods as offshoots of the communicative approach. At the same time, the learners were also encouraged to think critically. After the instruction of the intended syllabus, participants basically showed a higher degree of awareness of global issues and the ability to analyze problems and apply critical thinking in their environment. They were also more effective and coherent in their class participation than in other classes.
\end{abstract}

Keywords: global education, content-based approach, task-based approach, critical thinking

\section{Introduction}

As a backdrop, everyone on Earth is correlated to each other socially in terms of culture, environment and politics. We are interrelated by culture through shared media, intercommunications, travel and migration, by economy due to global trade, by environment through sharing one planet and by politics through international relations. In spite of the fact that we are living in the media age, we continue to face hurdles blocking global awareness such as 'information overload'. Usually, what is set forth by the media regarding global issues is hardly analyzed, either rationally or morally, in terms of reasons and causes. The information is imparted in a straightjacket manner, with no opportunity for critical thinking, nor does it offer any involvement in solving the stated issues, sometimes for political expediencies. If we wish to prepare young people for these challenges, to secure their well-being, and encourage them to build a better world than the one they have inherited, it is ideal to provide the learners in the classroom setting with the knowledge, skills and values they will need. These factors will not only activate schemata but also do it ethically. In addition, it is also ideal to provide a platform for critical thinking which allows people to handle the opportunities and challenges they encounter.

With the above as our background, as language teachers we are most fortunate of teachers...all subjects are ours. Whatever our learners want to communicate about is our subject matter (Rivers, 1976). English language teachers play a key role in preparing students for wider participation in global society. They can open a window of opportunity to develop the thinking skills as well as the communicative skills of students by using challenging materials on global issues. We cannot call our English teaching successful if our students, however fluent, are ignorant of world problems, have no social conscience by using their communication skills for international crime, exploitation, oppression or environmental destruction (Cates, 1997).

\section{Global Education}

\subsection{Definition}

Global issues are referred to "issues of global significance" (Anderson 1996), or "problems in the world" (Mark, 
1993). The global issues approach includes all problems affecting world citizens such as: globalization, poverty, peace, environment, and human and animal rights. They are not just a personal but also a professional concern of teachers in every branch of education (Reardon, 1988). According to Tye and Kniep (1991), global education "involves learning about those problems and issues which cut across national boundaries and about the interconnectedness of systems - cultural, ecological, economic, political, and technological." It prepares students to be active and engaged participants in an interrelated world.

\subsection{Rationale of Global Education}

Living in the ever shrinking world demands a perfect understanding and a sense of responsibility to deal with the issues that affect the citizen's lives. World problems are interconnected and global citizens are intrinsically dependent on each other. Industries in developed countries, for instance, are in part dependent on raw materials provided from underdeveloped countries. Many industries outsource their product to cut down their production costs. Taking a nonchalant and disinterested attitude to global events resembles the scenario where the passengers on a journey on board the same boat speculate that someone drilling his place will not hurt them and hence do not interfere, and only when others take prompt action, it triggers any response. The need for taking collective actions is seen to resolve many global problems. There is an urge for all countries to join the Kyoto Protocol in a bid to fight global warming which is a protocol to the United Nations Framework Convention on Climate Change (UNFCCC or FCCC) and has been signed by 191 states. On the basis of this treaty all the member countries have become obliged to tackle greenhouse gas concentration in the atmosphere. Dealing with such issues is a part of the social responsibility of all global citizens.

\section{Curriculum and Global Education}

Whether global issues suit and foster a curriculum in all areas of education depends on our view on a curriculum and what outcomes are set to be achieved. A 'real' curriculum is not just some predetermined learning materials to develop some literacy skills or instruct a specific subject matter in an offered course at school or university, but it tends to be more comprehensive than what many perceived in the past. In fact it aims to cultivate more 'well-rounded' citizens who perform their social functions more efficiently. This can never be gained by only acquiring knowledge of a single subject area; rather learners need to enhance their cognitive skills as an essential prerequisite which functions broadly in their daily lives. Ross (2004) states these skills may be gained through any socially structured or prescribed activities, selected in some way from the culture of that society, that result in the transformation of the individuals. The integration of global education in curriculum encourages learners to reflect on causes of issues and also find viable solutions to problems they face in society. They produce knowledge by reasoned interpretations through a process after receiving information. Smith, Stanley and Shores (1950) define curriculum as a cultural reproduction in a structured way which should also value independent thinking in the context of the widest sense of social responsibility. That is, a liberal and progressive curriculum requires to meet reasonableness, agency, a sense of relationship, and morality (Fenstermacher, 1994, as cited in Kridel, 2010). It prevents the learners from developing biased ideas, and helps them understand the connections among peoples, cultures, and environments around the world (Canadian Teachers Federation, 2005). Such content makes the curriculum authentic and learning more meaningful.

\section{Global Education Curriculum and Second Language Learning}

\subsection{Outcomes of Global Education Based Language Curriculum}

Language teaching through global education curriculum aims to produce a range of outcomes, including global awareness as well as cognitive and communicative outcomes. Each of these is attained through the class input and assigned tasks and learning strategies. Second language learning needs to be fueled with appropriate communicative tasks and opportunities for exercising the correct language usage in the class. Tasks are devised in a manner to make learners practice critical thinking which facilitates interaction between communication components. The students' improved ability in evaluating texts critically accounts for their successful communication in a second language. Therefore, the use of global issues curriculum in language classes is well justified when it raises global awareness and meets second language learning objectives.

\subsubsection{Second Language Learning}

The present view on second language acquisition is derived from our attitude to the nature of language and language learning. Language is regarded as a "dynamic resource for creating meaning" (Nunan, 2004), and second language acquisition is a conscious psycholinguistic process enabling learners to use forms of language to interact and communicate. Thus, being able to communicate meaning can be considered the most prominent objective of learners in every second language learning class. Swain (1985, as cited in Nanan, 2004) states in 
addition to input which is necessary, learners need opportunities to produce the target language. Learners tend to have different understandings and views about the things going on in their environment. This can provide certain conditions that are needed to negotiate for meaning in communicative tasks provided the teacher employs appropriate tasks and strategies. Pica et al. (1993, as cited in Nunan, 2004) name holding different portions of information, and exchanging the information for the successful completion of the task as two of the important conditions required for optimization of negotiation of meaning. With such an input a teacher can easily benefit from 'jigsaw' tasks, which are inclusive of the 'information exchange' task, the 'problem solving' task, the 'decision making' task, and the 'opinion exchange' task. All of the above elements, including input, tasks, and conditions engage learners in a global education curriculum language class in meaning-focused, communicative tasks rather than form-focused drills and exercises which is one of the implications of the acquisition-learning hypothesis for TBLT (Pica et al., 1993, as cited in Nunan, 2004).

\subsubsection{Development of Cognitive Skills and Global Awareness}

English language teachers can develop students' cognitive skills coupled with education for global citizenship. This develops global awareness and enhances the cognitive skills of learners. Global issues materials as input give learners ample opportunities to think critically, develop cognitive skills, and to negotiate meaning. Explicit instruction of critical thinking and using strategies such as questioning, negotiation, and cooperative tasks, make learners think critically about the world issues as they exchange ideas, evaluate each other's ideas critically and reason their own statements.

\section{Content-Based and Task-Based Methods in a Global- Issues Based Curriculum}

Content-based and task-based instructions are part of the communicative methodology which is effectively used in TESOL classrooms with global content. Task- based language teaching is based on the use of communicative and interactive tasks as central units for the planning and delivery of instruction. They provide an effective basis for language learning since they involve meaningful communication, interaction and negotiation and enable the learners to acquire the grammar as a result of engaging in authentic language use (Richards \& Schmidt, 2002). Content-based teaching argues that language is most effectively learned in the context of relevant, meaningful, motivating content which stimulates students to think and learn through the use of the target language (Cates, 1997). Language learners must be provoked, engaged and activated in the process of learning. This is a general criterion recommended to all English language educators.

Content educators such as Mohan (1986) advised the use of motivating themes and authentic materials in language teaching. Global issues are real issues: the spoiling of the rainforests, the thinning of the ozone layer, acid rain, nuclear waste disposal, exponential population growth, the spread of AIDS, state violence and genocide in Kurdistan, Tibet and Bosnia, ecological disaster compounded by war in Ethiopia and Somalia; the list is depressingly long (Maley, 1992). Language learners will be motivated when they find out that their prior knowledge, experience, concepts and ideas are being used as an avenue to understand global content being taught in the classroom. When they deal with the content relevant to real life situations, they actively participate and follow instruction in the classroom. 'Contentless' materials are not considered meaningful by learners and, therefore fail to provoke their curiosity. It cannot hold their interest.

Similarly, task-based language teaching method relies heavily on the learners' involvement and values their world knowledge and experience which they bring to the classroom. In the task-based method, as the learners exchange their knowledge, experience and opinion, they also use their existing knowledge of English, and are exposed to a new language. This develops different strategies for improvement of their language skills.

Applying Task-based language teaching (TBLT), English teachers use global issues, and authentic topics, issues which learners are trying to make sense of such as poverty, inequality, environmental change and so forth to encourage the development of skills necessary for the successful completion of the real- life tasks. Learners, meanwhile, are exposed to the target language in a naturally occurring context - material that is not specifically prepared for the language classroom.

World problems as the content of general English education meets both the need for more meaningful content, and argues that the educational content of general English education lacks meaning (Maley, 1992). Education is meaningful to the extent that it engages learners in reflecting on their relationship to the world they live in and provides them with a means to shape their world (Freire \& Macedo, 1987).

Language pedagogy approaches the need to focus its concern with language data, information, and opportunities for practice. Task-based as well as content-based language teaching has argued for the importance of incorporating authentic data which can be provided by global issues into the classroom. As a syllabus designer 
dealing inevitably with global issues such as content and topic, we have to consider the selection, sequencing and justification of the content of the curriculum, and the selection, according to task-based language teaching approach. Accordingly, in selecting teaching materials with global issue content, a prospective teacher or organization should consider some general principles such as the vocabulary load and the patterns which are to be gradually mastered (Lado, 1964). This fosters the aims of our language learning classroom, because the attention of learners will be focused more on predetermined linguistic content. However, it does not mean that every lesson, every reading passage, every group discussion should be about global concerns (Jacobs \& Cates, 1999). World issues which have been brought up in the classroom must meet the needs and interests of the learners. Candling and Murphy (1987, as cited in Larsen-Freeman, 2000) note language learning tasks should be presented in the form of a problem-solving negotiation between the knowledge that the learner holds and new knowledge.

\section{Critical Thinking and Global Issues in the Language Class}

\subsection{Introducing Critical Thinking and Global Issues}

Critical thinking and global education curriculum are essential components that should be integrated in language classes. Critical thinking never emerges automatically or accidentally. Rather it is a result of attentive application of language teaching strategies as well as appropriate input in the classroom. Language classes can also introduce global issues such as: world peace, environmental issues, child labor, poverty, and so on as the content. This input can be provided by a teacher, a textbook, and even by learners themselves from a rich variety of resources. The authentic nature of global problems, the diverse ideas existing about the causes, the open-endedness of possible solutions, and the differing knowledge levels of students about the problems allow the teacher to enhance the learners' cognitive skills such as critical thinking, creative thinking and so on. Critical thinking is one of the two known learning platforms. Critical thinking is also important in the acquisition of language skills. It is based on reasoning on the lesson, sentence, word, phrase till a logical understanding is firmly in place in the mind which is often emerged through questioning, root exploration, assessing the validity and so forth. Some of the advised strategies that can be used in the language classes for attaining both global awareness and critical thinking are questioning either in the form of reciprocal peer questioning in small groups followed by class discussions or readers' questions on an assigned reading passage (King, 1995), "Discussion Method"(McDade, 1995), "Conference Style Learning" (Underwood \& Wald, 1995) and "Cooperative Learning Strategies" (Cooper, 1995). These strategies encourage language learners to question the validity of ideas in texts or judge the ideas of other people.

\subsection{Critical Thinking and Second Language Speaking Skill}

Critical thinking has been proved to be important in acquisition of second language learning skills particularly writing and reading (Stapleton, 2001). In writing, it helps learners to analyze the essay question, identify the key issue, consider its different aspects, use their life experience for better understanding, and develop their own well-reasoned opinion before coming to a conclusion. Critical thinking improves speaking skills in similar ways.Firstly, critical thinking which is mostly developed in discussion tasks develops the areas of organizing key concepts, formulating arguments, testing ideas, problem solving and evaluating evidence (Davis, 1993). Critical thinking and discussion support each other, and critical thinkers are 'signposted' to appraising the arguments on the basis of the collected and collated data. Secondly, it empowers the speaker to identify the arguments in conversations and to evaluate the trustworthiness of the reasons. Finally, in addition to the inevitable limitations of spoken language, second language learners tend to have linguistic limitations on contributing to discussions and debates both in academic settings and real life situations within society. Critical thinking compensates for some linguistic inadequacies of language learners in speaking. Metacognitive awareness caused by critical thinking instruction as well as the two aforementioned reasons account for critical thinking integration in a speaking course.

\section{The Theory of Global Education in Practice}

This practice was done to evaluate the impact of application of global issues as the content of syllabus in an English conversation class where a questioning, discussion method, cooperative learning and conference style were used as strategies to approach global issues raised in the class. For this purpose, a content- based syllabus including ten passages presenting global issues was devised. A global issue was discussed in each session. Learners' performance was observed and reported throughout the course in terms of awareness of global issues, ability to analyze global problems, and linguistic ability.

\subsection{Participants}

This study was made on an intact group of intermediate English learners as a second language, at IOLS, Mysore, 
India. The participants' age was between twelve and nineteen years old. They were studying at intermediate level.

\subsection{Methods of Application \& Application Strategy}

In order to put the said strategies and methods into practice, a lesson plan was drawn up for each lesson. Then the performance of students was evaluated throughout the course. A passage of the provided syllabus and the method and strategies applied are illustrated below. This passage which presents the global problem of migration was adopted from 'the International Fund for Agricultural Development' website on migration.

\subsection{Class Application}

To introduce the topic as a warm up activity there is no need to define the problem, but rather it can be started from scratch. For instance, the meaning of the term migration was asked in the beginning. Then, to help the students to refer to their experience, it was asked where they had observed this phenomenon? Then, we went deeper and asked if it could be a problem? To progress further, learners were divided into groups of 3-5 and then read the distributed passage on massive migration from rural areas. (The topic was found suitable since the participants were from various countries and exhibited versatile cross-cultural background. Kindly refer appendix). Learners were encouraged to ask each other the following proposed questions.

1) How could "migration" be described, according to you?

2) Is this a common phenomenon in the present modern world?

$3)$ Is this issue a common problem in your country?

4) Why, according to you, is rural migration a booming reality?

5) Explain and illustrate your points using your personal observations and experiences?

6) What effect does migration have on rural areas?

7) How does it affect the socio-culture of cities?

8) Does rural migration have any effect on the mind-set of urban people?

9) How can governments prevent massive migration from rural areas to cities?

10) What solutions would you advise if you were the head of the government?

They also were encouraged to think of further extended questions on the topic. The participants learn to think and contribute their opinions in group discussion. While the teacher monitored the discussions, the primary focus was on the content being expressed. Since more streamlined vocabularies were deemed fit, they were asked to share the relevant words by hanging their list on the wall. Then, some of the learners from the student group were called in front of the class and the remaining students asked their questions related to the topic. Meanwhile, the learners were asked to be creative and were told to give ideas, both pros and cons. At the end of the class, a student was asked to give a short talk about the topic and possible causes discussed.

For such a purpose, for example, the teacher raised questions about the topic on the global issue that was due to be discussed. Then, the students focused mainly on the lesson material in terms of content. Finally, the learner used the language as freely and communicatively as possible by involvement in activities like discussion and conference.

\section{Result}

The results noted were appreciable and as planned. Primarily, the participants showed an increased degree in attentiveness. They also showed an increased development in the ability to think freely about global issues and their level in topic-based-free-thinking was much higher when compared to the past. Students successfully analyzed the global issues and the level noted was coherently demonstrated. The participants also showed a higher degree of understanding of global topics and it was observed that the level exhibited by them was above average. They were able to apply their personal experiences and demonstrated the same with others. It was observed that the interest level generated was relatively high in the class. The participants were enabled to get a clear idea on global issues and relate them to their own countries. This level of content - task performance by the participants in the class was much higher. After the instruction, they were obviously able to identify various world views and apply them in practical discourse thus increasing the interest and involvement by the participants. Global-issues-based curriculum proved that it can promote tolerance and appreciation of different beliefs, cultures and backgrounds. Finally, the participants provided rationales and balanced solutions to the various global problems encountered. Their cohesion and coherence including the task response was much higher than before. 


\section{Acknowledgments}

I thank Dr Benjamin Sukumar who allowed me to conduct this practice at the Institute of Language Studies, IOLS, Mysore, India, which is an International language teaching institute with students from around 31 countries. The Institute provided the right platform for the project application.

\section{References}

Anderson, G. G. (1996). Global Issues in the University ESL Classroom. The Language Teacher Online. Retrieved from http://jalt-publications.org/tlt/articles/2066-global-issues-university-esl-classroom

Cates, K. A. (1997). New Trends in Global Issues and English Teaching. The Language Teacher. Retrieved from http://jalt-publications.org/old_tlt/files/97/may/cates.html

Canadian Teachers Federation. (2005). Guide to Infusing Global Education into the Curriculum. Retrieved from www.global-ed.org/curriculum-guide.doc

Cooper, J. L. (1995). Cooperative learning and critical thinking. Teaching of Psychology, 22(1), 7-8. http://dx.doi.org/10.1207/s15328023top2201_2

Davis, B. G. (1993). Tools for Teaching (pp. 106-116). Jossey-Bass Inc., US.

Freire, P., \& Macedo, D. (1987). Literacy: Reading the word and the world (p. 106). South Hadley, MA: Bergin $\&$ Garvey.

IFAD. (2007). Lack of investment in agriculture is driving massive migration from rural areas, experts said at IFAD Governing Council meeting. Retrieved fromhttp://www.ifad.org/media/press/2007/15.htm

Jacobs, G. M., \& Cates, K. (1999). Global education in second language teaching. KATA, 1(1), 44-56. Retrieved from http://dx.doi.org/10.1109/2.901164 Global \% 20in\%Second\%Language\%20TeachingKATA.doc

King, A. (1995). Designing the instructional process to enhance critical thinking across the curriculum: Inquiring minds really do want to know: Using questioning to teach critical thinking. Teaching of Psychology, 22(1), 13-17. http://dx.doi.org/10.1207/s15328023top2201_5

Kridel, C. (Eds.) (2010). Encyclopedia of Curriculum Studies (Vol. 1, pp. 966-967). London, England: Routledge.

Lado, R. (1964). Language Teaching A Scientific Approach (pp. 52-53). McGraw-Hill.

Larsen-Freeman, D. (2000). Techniques and Principles in Language teaching (2nd ed.) (p. 144). Oxford University Press, New York.

Maley, A. (1992). Global issues in ELT. Practical English Teaching, 13(2), 73.

Mark, K. (1993). Some thoughts about "global" content. The Language Teacher, 17(5), 37-40.

McDade, S. A. (1995). Case study pedagogy to advance critical thinking. Teaching Psychology, 22(1), 9-10. http://dx.doi.org/10.1207/s15328023top2201_3

Mohan, B. (1986). Language and content (pp. 21-23). Reading, MA: Addison-Wesley.

Nunan, D. (2004). Task-based Language Teaching (p. 6, 77, 80, 84). Cambridge University Press.

Reardon, B. (1988). Comprehensive peace education: educating for global responsibility. New York: Teachers College Press.

Richards, J. C., \& Schmidt, R. (2002). Language Teaching \& Applied Linguistics Dictionary (3rd ed.) (p. 540).

Rivers, W. (1976). Speaking in many tongues: Essays in foreign language teaching (2nd ed.) (p. 105). Rowley, MA: Newbury House.

Smith, B. O., Stanley, W. O., \& Shores, J. H. (1950). Fundamentals of Curriculum Development. New Wold Education Series, Publisher: World Book Company.

Ross, A. (2004). Curriculum Construction and Critique (p. 8). Faler Press Garlan Inc.

Stapleton, P. (2001). Assessing critical thinking in the writing of Japanese university students: Insights about assumptions and content familiarity. Written Communication, 18(4), 506-548.

Tye, K. A., \& W. M. Kniep. (1991). Global education around the world. Educational Leadership, 48(7), 47-49.

Underwood, M. K., \& Wald, R. L. (1995). Conference-style learning: A method for fostering critical thinking with heart. Teaching Psychology, 22(1), 17-21. http://dx.doi.org/10.1207/s15328023top2201_6 


\section{Appendix}

\section{Lack of investment in agriculture is driving massive migration from rural areas, experts said at IFAD} Governing Council meeting (IFAD, 2007).

Rome, 16 February 2007 - The number of people migrating in search of a better life is on the rise worldwide, and the vast majority of them are from poor rural areas, experts reported at a round-table discussion at the Governing Council meeting of the International Fund for Agricultural Development (IFAD).

Lack of productivity in agriculture is the main reason for high levels of rural out-migration, said Aziz Khan, professor at the School of International and Public Affairs at Columbia University in New York City. "Poor rural people need to be able to make a living from agriculture - or we need to help them find alternative sources of income," said Dr Khan. "Lack of infrastructure such as roads to reach the nearest market or the nearest hospital is also a major cause of migration," said Rosemary Vargas-Lundius, a policy coordinator at IFAD.

Rural development policies should focus on promoting initiatives that reduce constraints provoking out-migration and support investment by migrants in their place of origin, said Vargas-Lundius. "Establishing adequate agricultural pricing and marketing policies, providing access to financial markets and promoting decentralization may help create an environment that encourages migrants to invest back in their countries."

Over the past 50 years, about 800 million people have moved from rural areas to cities and to foreign countries. Although international migration has a higher profile, for every person who has migrated to a foreign country seven more people have migrated domestically, said Frédéric Sandron, research officer at the Institut de recherche pour le développement in Paris.

One of the downsides of migration, experts say, is that it robs rural society of its most productive and skilled workers - usually young people. In some countries, it is rural women who are increasingly leaving home in search of employment - another aspect of migration that is changing the social and demographic face of rural life.

The international community is not going to be able to halt the tides of rural migrants, said Dr Khan, but it can make migration "more organized and more effective."

One way to accomplish this, he suggested, is to link migrants' remittances to formal banking systems, particularly locally based savings and loans associations. Recent research suggests that the money migrant workers send back to rural areas has overtaken agriculture as the main source of income.

Many rural migrants are heading towards medium-sized cities with populations of 500,000 or less, reported Cecilia Tacoli, senior researcher at the International Institute for Environment and Development. "We need to remember the important role these medium-sized cities have in the rural economy," said Tacoli. "Not only are they a source of income for migrants but they also represent an important market opportunity." In Africa, for instance, approximately 80 per cent of the food consumed in medium-sized towns comes from nearby rural areas, she said. Panelists agreed that migration should be available as an option for rural people - but that it should not be the only means of survival for them.

"In some Latin American countries, cultural aspects drive migration as much as economic ones," said Benjamin Davies, an economist for the Food and Agriculture Organization of the United Nations (FAO).

\section{Copyrights}

Copyright for this article is retained by the author(s), with first publication rights granted to the journal.

This is an open-access article distributed under the terms and conditions of the Creative Commons Attribution license (http://creativecommons.org/licenses/by/3.0/). 